\title{
O Deserto dos Mestiços: O Sertão e seus Habitantes nos relatos de viagem do início do Século XIX
}

Luiz Francisco Albuquerque de MIRANDA*

\begin{abstract}
Resumo: $O$ artigo analisa as representações do sertão presentes nas obras dos viajantes e naturalistas August de Saint-Hilaire e Johann von Spix \& Carl von Martius, que percorreram a América portuguesa no início do século XIX. A investigação restringe-se aos relatos de viagens pelo interior das províncias de São Paulo, Minas Gerais e Goiás. Os naturalistas, orientados pelos referenciais da cultura européia, esforçaram-se para conhecer e compreender regiões que ainda não eram consideradas civilizadas, mas estavam na fronteira da colonização. O sertão, definido como ambiente bárbaro e desértico, representa um desafio para os cientistas, que projetavam o progresso da sociedade brasileira.
\end{abstract}

Palavras-chave: Sertão; Civilização; Saint-Hilaire; Spix \& Martius.

\section{Introdução}

A chegada da família real na América portuguesa em 1808 abriu um ciclo de viagens de cientistas, comerciantes, missionários e artistas de várias partes da Europa em busca de um conhecimento mais preciso da flora, fauna e geografia da região. Os viajantes também procuravam caracterizar os tipos humanos e avaliar se a sociedade havia caminhado no sentido de estabelecer a vida civilizada nos trópicos.

Buscando um aproveitamento mais intenso, rápido e eficaz dos recursos humanos e materiais oferecidos pelas diversas partes do planeta, os cientistas viajantes produziram

\footnotetext{
- Professor Doutor - DECIS - Universidade Federal de São João del-Rei - UFSJ - 36.301-160 - São João del-Rei - MG - Brasil. E-mail: lfamirranda@uol.com.br
} 
conhecimentos capazes de identificá-los e avaliá-los, oferecendo parâmetros para repensar as relações entre a Europa e os outros continentes. Em seus relatos, também procuravam superar a sensação de caos decorrente do contato com a natureza desconhecida e sociedades diversas.

Desde os primeiros exploradores, a América foi vista como a terra de homens rústicos, sem história, que deveriam ser cristianizados. Com a colonização das áreas costeiras do continente, as populações interioranas continuaram a ser identificadas como selvagens. Por outro lado, a idéia de progresso, que se consagrou ao longo do século XVIII, contribuiu para apontar um sentido universal para o avanço da expansão européia em mundo todo. Para viabilizar o avanço do processo civilizador, os europeus acreditavam que deveriam governar diretamente imensas regiões da Ásia e da África, ou ajudar a corrigir os erros e os abusos das jovens nações americanas. Em geral, o cientista viajante do século XIX desempenhava de bom grado o papel de conselheiro das elites da América do Sul, responsáveis pela eliminação da barbárie no interior do continente.

Analiso neste texto a obra de três naturalistas: o francês Auguste de Saint-Hilaire e a dupla alemã Carl F. von Martius e Johann B. von Spix. O primeiro visitou o centro-sul do Brasil entre 1816 e 1822 e escreveu a respeito das províncias de Minas Gerais, Rio de Janeiro, Espírito Santo, São Paulo (que incluía o atual estado do Paraná), Goiás, Santa Catarina e Rio Grande do Sul (LIMA, 2002). Os alemães, de 1817 a 1820, percorreram juntos uma vasta área de São Paulo ao Amazonas (LISBOA, 1997).

Os trabalhos desses viajantes apresentam diversas semelhanças. Todos eram naturalistas (Saint-Hilaire e Martius, botânicos, Spix, zoólogo) e membros de academias de ciências. De alguma forma, estavam articulados com o poder estatal: os alemães vieram em missão oficial, pois foram enviados pelo rei da Baviera, Maximiliano José I, na comitiva da filha do arquiduque da Áustria que casaria com Pedro de Alcântara (futuro D. Pedro I) no Rio de Janeiro; o francês chegou ao Brasil acompanhando o embaixador de sua nação. A Coroa lusitana parece ter visto com bons olhos a presença dos cientistas, pois as autoridades locais, 
O DESERTO DOS MESTIÇOS: O SERTÃO E SEUS HABITANTES...

segundo os relatos dos próprios viajantes, ofereceram cartas de recomendação, alojamentos e isenções fiscais - de pedágios, por exemplo - que facilitaram suas viagens pelo interior.

Em razão dos percursos escolhidos por esses pesquisadores, que se afastaram das costas e privilegiaram áreas do interior, encontramos em suas obras muitas referências ao sertão e aos sertanejos. Vale lembrar que, no presente estudo, não trato das representações dos povos indígenas. Meu interesse concentra-se nas imagens dos homens que estavam na fronteira da colonização européia. Mesmo admitindo as singularidades dos relatos de cada viajante e reconhecendo que o impacto do estranhamento conduz a percepções ambíguas, acredito que os naturalistas compartilharam certas referências posteriormente utilizadas por muitos intelectuais brasileiros.

Antes de prosseguir, é preciso lembrar que os relatos de viagem, antes de serem publicados, passavam por um complexo processo edição. A longa preparação dos textos de Saint-Hilaire é um caso particularmente expressivo. O francês voltou para a Europa em 1822, mas apenas em 1830 publicou o primeiro volume de Voyage dans l'intérieur du Brésil, coleção de descrições de diversas regiões brasileiras publicadas ao longo das décadas de 1830 e 1840. Antes, ele publicou alguns textos bem menores com observações muito gerais a respeito da viagem, como o Aperçu d'un Voyage dans l'interieur du Brésil de 1823, ou trabalhos mais específicos a respeito de problemas botânicos (LIMA, 2002: 143151). Obviamente os relatos foram compostos a partir de notas tomadas pelo autor no decorrer das viagens, mas também apresentavam comentários e notícias que indicavam o processo de reescrita dos primeiros manuscritos, evidenciando o esforço de assimilação de dados e representações a respeito do Brasil presentes em obras que circulavam nos meios literários e científicos europeus. Em seus trabalhos, o naturalista citou diversos autores (viajantes, missionários, autoridades estatais, literatos e cientistas) que ajudaram a formular suas opiniões e enriqueceram suas descrições. Portanto, os relatos não 
exprimiram apenas as impressões imediatas de Saint-Hilaire, pois resultaram do conhecimento de outros pesquisadores e do estudo de muitos documentos aos quais ele teve acesso. Algo muito semelhante certamente pode ser dito a respeito dos trabalhos de Spix \& Martius.

\section{Sertão como "deserto"}

Roberto Ventura, comentando Euclides da Cunha, nota que o escritor descreveu tanto a Amazônia quanto o sertão baiano como "paisagem fantástica ou maravilhosa, que paralisa o observador, tomado por um misto de terror e êxtase". Na descrição dos dois ambientes, Cunha recorreu à imagem do "deserto":

Selva e sertão são vistos como desertos por seu isolamento geográfico e povoamento rarefeito, e, sobretudo, por serem territórios ainda não explorados pela ciência, que os viajantes evitavam e que os cartógrafos excluíam de seus mapas. (...) Sertão é, para Euclides, tudo aquilo que está fora da escrita da história e do espaço da civilização: terra de ninguém, lugar da inversão de valores, da barbárie e da incultura. São territórios misteriosos, fora da história e da geografia, que não foram mapeados de forma sistemática. (VENTURA, 1998)

Para compreender os significados da representação do sertão na cultura brasileira é necessário ter em mente o conjunto imagético assinalado por Ventura. De minha parte, sugiro que Euclides da Cunha recupera uma imagem tradicional quando caracterizou como desertos as florestas, os cerrados e as caatingas do interior do país, pois representação semelhante aparece com muita freqüência nos relatos de viagem do início do século XIX.

Vejamos como Spix \& Martius (1976: 50) descrevem a parte "menos povoada" de Minas Gerais: o sertão. A palavra mobiliza uma rede de significados. Narrando a travessia da fronteira do termo de Minas Novas na mesma província, os alemães afirmam: 
O DESERTO DOS MESTIÇOS: O SERTÃO E SEUS HABITANTES...

"achamo-nos agora no sertão, como denominam os mineiros a vastidão deserta, na sua linguagem usual" (SPIX \& MARTIUS, 1976: 65). Enquanto atravessam o interior mineiro, eles recordam tradicionais imagens bíblicas: "encontrávamos freqüentemente nuvens de pó negro, em cuja base chispavam faíscas, fazendo-nos lembrar as colunas que precediam os israelitas no deserto, indicando-lhes o caminho" (SPIX \& MARTIUS, 1976: 97). Esta referência à imagem judaico-cristã do deserto bíblico ajuda a entender um dos significados da palavra sertão nos relatos: como o povo de Deus, o cientista, para cumprir seu destino, precisa enfrentar lugares ameaçadores e desconhecidos, onde seria fácil perder o verdadeiro sentido da viagem. A travessia do sertão, "terra maravilhosa, ainda que igualmente cheia de perigos" (SPIX \& MARTIUS, 1976: 62), testa a perseverança do homem de ciência.

Para compreender essas referências, parece-me útil lembrar alguns traços das representações do deserto na cultura ocidental. No texto de Spix \& Martius é possível identificar resíduos do que Le Goff (1985: 39-45) chama de "epopéia do deserto": herdeiro de tradições mais antigas, o cristianismo medieval representa 0 deserto como lugar maravilhoso, sujeito às tentações do demônio, no qual monges, cavaleiros e santos, em peregrinação, enfrentam provas e cumprem penitências. Para encontrar a verdade e provar suas convicções, o homem, quando tem uma missão elevada a cumprir, deve enfrentar o arriscado deserto. Os naturalistas, missionários da ciência, parecem percorrer o inóspito sertão recordando o imaginário tradicional.

Descrevendo áreas do oeste de Minas Gerais, Saint-Hilaire (1975a: 92) também apresenta o sertão como "região desértica". Em outros relatos, o viajante francês insiste na caracterização. De Goiás até a região central de São Paulo, "os descendentes dos portugueses não ocupam (...) mais que uma estreita faixa de terreno, além da qual estão situados imensos desertos" (SAINTHILAIRE, 1972: 112). O trajeto de Lajes, Santa Catarina, até a cidade paulista de Sorocaba, percorrido por tropas de muares, também é descrito como um "sertão, imenso deserto coberto de matas" (SAINT-HILAIRE, 1972: 233). Mais uma vez, notamos a presença de resíduos da cultura ocidental que remontam à Idade 
Média. Le Goff (1985: 46) assinala que, para os medievais, "o deserto - o mesmo é dizer, a solidão - assumirá um aspecto absolutamente diferente (...) do deserto sob o aspecto da geografia física: será a floresta". O deserto-floresta reaparece no discurso dos naturalistas. Essa aparição torna-se ainda mais expressiva quando pensamos no seu significado para o medievo: além de lugar solitário, cenário de penitências que depuram e santificam, representa o asilo dos marginalizados, onde vivem loucos, amantes fugitivos, vagabundos e trabalhadores de menor prestígio como os caçadores, carvoeiros e coletores, todos suspeitos para os homens dos castelos e das cidades. No caso, o deserto-floresta é a fronteira entre a vida humana e a animal. Os indivíduos ali encontrados são selvagens e, para o medievo e talvez para toda cultura ocidental, "o selvagem é, não o que está fora do alcance do homem, mas o que está nas margens da atividade humana" (LE GOFF, 1985: 127). Portanto, desde a Idade Média, os europeus opõem o mundo selvagem da floresta à sociedade organizada, ou seja, à corte, à cidade, aos castelos e suas plantações. Penso que as referências ao sertão brasileiro atualizam as imagens tradicionais da floresta: como esta, aquele é definido como "deserto".

Segundo Janaína Amado (1995: 4), a palavra sertão começou a ser utilizada pelos portugueses no final da Idade Média, "com certeza desde o século XIV", "para referir-se a áreas situadas dentro de Portugal, porém distantes de Lisboa". Assim, "a partir do século XV, usaram-na para nomear espaços vastos, interiores, situados dentro das possessões recém-conquistadas ou contínuos a elas, sobre os quais pouco ou nada sabiam". A palavra, portanto, tem uma origem medieval e na Renascença nomeava regiões fora do controle da Coroa portuguesa. Durante todo o período colonial, o termo foi amplamente utilizado pelas autoridades lusitanas na América para designar "áreas extensas afastadas do litoral, de natureza ainda indomada, habitada por índios selvagens e animais bravios" (AMADO, 1995: 6).

Mesmo admitindo que as imagens tradicionais da floresta oferecem muitos elementos para a representação do sertão, é necessário apontar as diferenças entre os dois universos 
O DESERTO DOS MESTIÇOS: O SERTÃO E SEUS HABITANTES...

simbólicos. Os medievais apresentam o deserto-floresta como o refúgio de marginalizados, porém, nele o fugitivo pode regenerarse e reconciliar-se com Deus e com a sociedade. Dessa forma, nas lendas, entrar na floresta é uma experiência extrema que resgata o valor dos personagens. O sertão brasileiro, desde o século XVI, também aparece como deserto ameaçador e misterioso. Todavia, ele representa um espaço a ser conquistado. Para exemplificar, lembro as Atas da Câmara da Vila de São Paulo do século XVII. Com alguma freqüência, a palavra está presente nestes documentos nomeando uma vasta área, mais ou menos indefinida, onde vivem "gentios" ferozes que matam e devoram homens brancos, povos que os paulistas podem e devem escravizar. No sertão, segundo uma Ata de 1606 (1915: II, 499), muitos indígenas "vivem a lei de brutos animais, comendo-se uns aos outros". Trata-se, mais uma vez, da fronteira entre o humano e o animal, mas agora ela é marcada pela guerra que submete o selvagem. Mais do que um refúgio, o deserto-floresta americano representa então um espaço aberto à conquista: é necessário dominá-lo e transformá-lo por meio do trabalho dos colonizadores. Para as comunidades feudais, a floresta apresenta-se como área de recursos indispensáveis e seu arroteamento gera prosperidade (LE GOFF, 1993: 289-310). Porém, no imaginário da Idade Média, ela é principalmente o limite da loucura e da aventura dos que, por algum motivo, não podem permanecer no mundo da ordem e da lei; é o terreno da iniciação que os reintegra. Ainda que marginal, ameaçadora e fonte de riquezas, a floresta do medievo não aparece como território a ser completamente ocupado, foco da intervenção transformadora capaz de lhe conferir um verdadeiro sentido histórico. Ora, é este exatamente o significado do sertão desde o período colonial. O deserto dos viajantes retoma o significado do sertão dos paulistas: trata-se, como sempre, da fronteira maravilhosa e regeneradora, mas que o europeu precisa ultrapassar, invadir e controlar. Por outro lado, diferente dos sertanistas, o homem de ciência do século XIX concebe o controle como resultado da pesquisa que deve explicar as características, os problemas e as possibilidades das regiões sertanejas. Estas devem ser conhecidas, pois não se admite a permanência dos 
mistérios que caracterizam o deserto-floresta medieval - a ciência deve ajudar a esclarecê-los e eliminar o caos.

Para entender como os viajantes concebem a conquista e a ocupação do interior da América portuguesa, volto aos relatos. Descrevendo a comarca de Paracatu em Minas Gerais, SaintHilaire (1975a: p.118) retoma o conjunto imagético a pouco referido:

A Comarca de Paracatu não passa, pois, de um imenso deserto.

Entretanto, não visitei o lado da comarca compreendida entre o São Francisco e a cadeia que, do lado oeste, fornece afluentes a esse rio. É de supor, porém, que esse trecho do sertão seja ainda menos civilizado do que o que eu havia percorrido na margem direita do São Francisco, já que se acha muito afastado do que se pode considerar como os centros civilizados da Província de Minas [Ouro Preto, São João del-Rei etc]. (...) Creio poder afirmar, entretanto, que os habitantes da região que atravessei para chegar a essa cidade [Paracatu] são constituídos pela escória da Província de Minas. (Grifos do autor)

Saint-Hilaire articula dois elementos na passagem acima: a imagem do "imenso deserto" e o conceito de civilização - este último inexistente nas representações dos paulistas do século XVII. Quanto aos sertanejos, distinguem-se dos moradores dos "centros civilizados". Nota-se que os habitantes do suposto deserto valem pouco, pois não passam de uma "escória". Assim, o que define o deserto brasileiro, habitado por índios e mestiços, não é exatamente a ausência de pessoas, mas a inexistência de vida civilizada, pois a presença dos sertanejos é claramente anunciada.

Analisando a emergência do conceito de civilização, Norbert Elias (1990: 26-27) observa como ele foi cunhado no século XVIII em países hegemônicos como Inglaterra e França, exprimindo "a consciência que o Ocidente tem de si mesmo", pois "resume tudo em que a sociedade ocidental dos últimos dois ou três séculos se julga superior a sociedades mais antigas ou a sociedades contemporâneas mais primitivas". O sertão não espelha a autoimagem dos europeus e parece quase impetrável ao progresso das 
Luzes e ao controle estatal. Portanto, além de recordar a mítica e misteriosa floresta medieval, o perigoso território dos marginais, o deserto selvagem do interior da América do Sul transforma-se em obstáculo a ser vencido pelos agentes do progresso.

É possível reencontrar esse conjunto imagético em várias passagens nas quais os viajantes manifestam angústia. Ao entrar em uma cidade depois de longa viagem, Saint-Hilaire (1975b: 6162) confessa o tédio provocado pelo sertão de Goiás: "Entediado pela triste monotonia da região, é com prazer que o viajante vê o encantador efeito produzido na paisagem pela série de construções regulares, que contrastam com o aspecto selvagem e desértico das terras circunvizinhas". A cidade de Vila Boa, capital de Goiás, para ele é "um oásis no meio de um deserto". É prazerosa a contemplação da regularidade produzida pelo processo civilizador, enquanto a paisagem selvagem deprime o naturalista. Todavia, por vezes, Saint-Hilaire (1975b: 110) deleitase com a solidão sertaneja: "A paz e a liberdade que eu desfrutava naquelas solidões seriam certamente um dia motivo de nostálgicas lembranças". Como alertei acima, os relatos de viagens apresentam ambiguidades.

Spix \& Martius (s/d: 128) também traçam comparações entre as paisagens civilizadas e as selvagens: na estrada entre Rio de Janeiro e São Paulo, as "belas roças de milho, mandioca e cana" causam "agradável impressão" aos naturalistas, mas as "matas virgens tenebrosas", apesar da aparência tranqüila, os angustiam e oprimem. Os alemães exaltam a exuberância das florestas tropicais, mas lembram que, no seu interior, "reinam trevas eternas" capazes de "apavorar a alma" (SPIX \& MARTIUS, s/d: 238). Reaparece a imagem do mítico deserto-floresta, escuro e misterioso.

É notável como os desertos do interior do Brasil inquietam os cientistas europeus, pois representam o caos improdutivo e angustiante, monótono ou pavoroso. No texto a respeito de Goiás, Saint-Hilaire (1975b, p.23-31) narra sua visita ao cume de um morro, promontório do homem civilizado, de onde avista terras "despovoadas e sem sinal de cultura". Porém, pouco depois, sua comitiva pára em um sítio "que se compõe de um aglomerado de 
humildes casebres". Nas páginas seguintes, o mesmo modelo descritivo repete-se: o autor afirma que atravessa áreas "despovoadas, incultas e sem sinal de gado", mas logo em seguida encontra uma "insignificante fazenda" com "casebres semi-arruinados". Vejamos uma passagem particularmente expressiva:

Até onde a vista pode alcançar não há o menor traço de cultura, o menor sinal de gado nos pastos, apenas uma profunda solidão, uma tediosa monotonia. Não existe ali nenhuma fazenda (1819), mas a algumas léguas de distância uns dos outros encontram-se, à beira da estrada, uns poucos e miseráveis sítios, e junto deles os indefectíveis ranchos abertos de todos os lados. (Saint-Hilaire, 1975b: 120)

Nas terras monótonas de Goiás, Minas Gerais e São Paulo, o entediado Saint-Hilaire encontra estradas com pousos para os viajantes, sítios e casebres pobres, lugares com nomes bem conhecidos, pessoas de aspecto humilde, até engenhos de açúcar e, entretanto, elas são definidas como desérticas e solitárias. A ausência de sinais de agricultura, pecuária, comércio, enfim, das formas capitalistas de produção, leva o viajante a sempre insistir na mesma imagem. Mas essas regiões carecem também de vida urbana, de gente alfabetizada, de agentes do Estado, enfim, de europeus. O sertão é deserto porque não sinaliza a existência da vida civilizada. Não estou insinuando que Saint-Hilaire e Spix \& Martius erram ao apontar a baixa densidade demográfica do interior do Brasil. Porém, a imagem do sertão monótono e caótico é mais que uma constatação. Definido como deserto improdutivo, precário e tedioso, o interior da América portuguesa aparece como área disponível para a ação do homem civilizado, o único realmente capaz de aproveitar seus recursos e instaurar uma ordem regular. Prevendo o progresso do sertão, o naturalista francês deseja que seu relato informe aos futuros brasileiros como era inútil e miserável o interior de seu país. O "Prefácio" de Viagem à província de Goiás é revelador: 
Mas aquelas belas regiões desérticas contêm os germes de uma grande prosperidade. Tempo virá em que cidades florescentes substituirão as miseráveis choupanas que mal serviam de abrigo (...). Nenhum outro francês, antes de mim, jamais percorrera Minas Gerais, Goiás, S. Paulo etc. Se alguns exemplares dos meus relatos resistirem ao tempo e ao esquecimento, as gerações futuras talvez encontrem neles informações de grande interesse sobre essas vastas províncias, provavelmente transformadas, então, em verdadeiros impérios. $\mathrm{E}$ ficarão surpreendidas ao verificarem que, nos locais onde se erguerão então cidades prósperas e populosas, havia outrora apenas um ou dois casebres que pouco diferiam de choças dos selvagens (...); que, em lugar das extensas plantações de milho, de mandioca, de cana-de-açúcar, e das árvores frutíferas, o que havia eram terras cobertas por uma vegetação exuberante mas inútil. (SAINT-HILAIRE, 1975b: 14)

Escrevendo para o futuro, o francês anuncia o destino do sertão: desaparecer e ceder lugar para a civilização, tornando-se "útil". O deserto-floresta está condenado, pois deverá participar do progresso da história universal. Seus habitantes, uma "escória" desprezível, será substituída pelos construtores de "impérios" que poderão notar, graças aos relatos dos viajantes pioneiros, o quanto contribuíram para a superação do caos e da barbárie. Assim, o naturalista desconsidera as experiências sociais das populações sertanejas: elas parecem incapazes de produzir efeitos históricos duráveis. O verdadeiro sentido da história do interior da América portuguesa é cumprir a sina de abrigar cidades, indústrias e agricultura mercantil. Saint-Hilaire não pode suportar a idéia de que esse mundo marginal, misterioso, selvagem e ameaçador continue a existir, pois ele "contém os germes" da mudança. A missão do viajante, depois de muito tédio e sofrimento, é anunciar o seu fim.

Saint-Hilaire e Spix \& Martius apresentam fórmulas discursivas semelhantes: representam repetidamente o sertão como deserto, mesmo deixando entrever os indícios da presença humana. Sendo assim, a imagem de um estado primordial e caótico, que deve ser substituído pela ordem civilizada, escamoteia a cultura e as formas de subsistência dos sertanejos 
do início do século XIX. Em nome do futuro, é necessário que o Estado, a Igreja e os empreendedores capitalistas dominem o interior da América do Sul, conduzindo sua história para o destino apontado pelos cientistas, a saber: o desenvolvimento dos "germens" de prosperidade dispersos nesse espaço fronteiriço entre a ordem e a desordem.

\section{O isolamento do sertanejo}

Para os naturalistas, o sertão é um deserto e seus habitantes vivem isolados. Spix \& Martius definem como "primitivos filhos da solidão" os moradores do norte e do nordeste de Minas Gerais. A definição, como em casos anteriores, comporta ambigüidades, pois os alemães valoram positivamente certos aspectos dessa primitividade. Apresento um exemplo. Os sertanejos mineiros, segundo os viajantes, manifestam um considerável "conhecimento prático" das possibilidades de utilização de plantas e animais nativos, algo decorrente de seu "contato com a natureza" (SPIX \& MARTIUS, s/d: 239-240). Os cientistas identificam o mesmo "conhecimento prático" nos "sertanejos de São Paulo":

O contínuo lidar com a natureza aguça o sentido desses homens simples, dando-lhes percepção tão exata dos característicos físicos, que, neste ponto, eles superam o europeu, muito ilustrado, mas pouco observador da natureza. (...)

Igualmente o sertanejo é notável pelo conhecimento perfeito das plantas medicinais de sua terra(...). É um erro julgar que esses conhecimentos práticos das virtudes curativas de plantas tenham, por tradição, sido herdados dos primitivos indígenas americanos pelas atuais gerações. (...)

O maior merecimento no achar e aplicar a virtude curativa das plantas (...) compete, pois aos paulistas. O seu gênio ativo e curioso, estimulado pela rica natureza, fê-los prosseguir nas descobertas casuais, ou, mesmo raramente, por indicação dos indígenas, feitas com a perspicácia própria do europeu. (SPIX \& MARTIUS, s/d: 171) 
O DESERTO DOS MESTIÇOS: O SERTÃO E SEUS HABITANTES...

O comentário acima encontra-se na narrativa de uma visita à região de Sorocaba. Nem sempre os caipiras de São Paulo são descritos pelos viajantes como portadores de "um gênio curioso e ativo". Mas é evidente que Spix \& Martius consideram o homem do sertão capaz de se aperfeiçoar intelectualmente e de aprender com a experiência. É bem verdade que eles não formulam sistemas explicativos complexos e universais, mas produzem "conhecimento prático" a partir de "descobertas casuais". Nem o europeu nem o indígena dominam esse conhecimento: o primeiro porque se afastou do mundo natural; já o segundo parece incapaz de adquiri-lo. Pode-se apontar aqui a valorização do homem natural, característica do Romantismo. Todavia, é importante observar a distinção estabelecida pelos alemães entre o paulista e o índio: não é simplesmente a proximidade com a natureza que possibilita ao primeiro conhecer as virtudes das plantas; ele manifesta um "gênio", uma potência ativa, capaz de superar e desenvolver as referências tradicionais recebidas dos indígenas. Por outro lado, Spix \& Martius atribuem ao caipira o poder de ensinar algo que o civilizado parece incapaz de descobrir por si mesmo. Assim, a passagem acima exemplifica como o impacto da viagem estimula interpretações que, de alguma forma, questionam a tradicional imagem de superioridade do europeu.

Entretanto, em contraste com o que observamos acima, Spix \& Martius frequentemente enfatizam a pequena vivacidade mental dos homens do interior. Vejamos como explicam o fracasso dos jornais no Brasil:

Pena é não serem lidos com interesse esses poucos jornais. Sobretudo o habitante do interior, gozando de generosa natureza rica, limitado à comunicação com poucos vizinhos afastados, manifesta pouca atenção pelos acontecimentos do mundo político, e satisfaz-se com a notícia dos principais sucessos que lhe trazem os guias das tropas, quando regressam da costa. (SPIX \& MARTIUS, s/d: 54)

O sertanejo conhece as plantas do local onde vive, mas ignora o resto da humanidade. Trabalhando apenas para 
satisfazer suas necessidades básicas e restrito a relações interpessoais limitadas, ele está afastado do "mundo político". Seu isolamento e sua economia de subsistência aparecem como empecilhos para seu aperfeiçoamento pessoal e inibem o progresso do Brasil. Ele experimenta um universo muito pequeno de contatos, o que torna desnecessária a obtenção de notícias a respeito de temas complexos e lugares longínquos. $\mathrm{Na}$ verdade, sua vida cotidiana pode ser conduzida sem o conhecimento profundo do que ocorre nas capitais ou em outras partes do planeta.

Spix \& Martius acreditam que amplos e intensos contatos interpessoais possibilitam o aprimoramento material e espiritual das sociedades. Uma rápida comparação entre os diferentes moradores do interior paulista explicita a tese: "Os habitantes de Taubaté mostram, de resto, mais conforto e educação do que os das pequenas vilas por onde havíamos passado antes, isto certamente devido às relações comerciais intensas com o Rio de Janeiro e São Paulo" (SPIX \& MARTIUS, s/d: 134). O progresso, portanto, depende da constância e intensidade dos contatos comerciais. "Conforto" e "educação", elementos característicos da vida civilizada, não derivam apenas das qualidades intrínsecas e do talento natural dos agentes sociais, resultam também das relações entre eles. Segundo os naturalistas alemães, os homens do interior, quando não se relacionam com os centros urbanos, o mercado capitalista, o Estado e a Igreja, permanecem como "primitivos filhos da solidão". O "gênio ativo e curioso" dos paulistas, sem aquelas ligações, não se aperfeiçoa e produz apenas conhecimentos práticos a respeito de seu ambiente selvagem. $O$ isolamento do morador do sertão-deserto mantém o estado de barbárie e inviabiliza sua contribuição para o progresso da sociedade.

Como Spix \& Martius, Saint-Hilaire aponta vários motivos para o comportamento rústico das populações do interior do Brasil e, mais uma vez, as relações interpessoais restritas, o isolamento e o desconhecimento do mundo exterior surgem como fatores decisivos. Poucos meses antes da Independência do Brasil, analisando os proprietários rurais de Mogi das Cruzes em São 
O DESERTO DOS MESTIÇOS: O SERTÃO E SEUS HABITANTES...

Paulo, o naturalista francês aponta o distanciamento do interiorano da vida política do Império luso-brasileiro:

Caiu a conversa sobre os acontecimentos do Rio de Janeiro. Tive a impressão de que estes homens não têm idéias sobre os fatos. Estão muito pouco a par dos fins colimados pela revolução de Portugal. Enfim, tanto desconhecem os interesses de seu país quanto fazem confusa idéia das relações do Brasil com a pátria mãe.

As agitações do Rio de Janeiro (...) foram promovidas por europeus, e as revoluções das províncias obra de algumas famílias ricas e poderosas. A massa popular a tudo ficou indiferente... (SAINTHILAIRE, 1974: 83-84)

O contexto a que o autor se refere é o da desobediência de D. Pedro, então príncipe de Portugal, às determinações das Cortes de Lisboa. A tradicional imagem do povo que assiste com indiferença os processos políticos, ou simplesmente os ignora, já se anuncia nos textos dos viajantes do século XIX. Os sertanejos "desconhecem os interesses de seu país" ou "fazem confusa idéia" das relações nas esferas do poder central, portanto não interferem nos processos históricos. Só os europeus, as elites urbanas e os homens muito ricos participam da vida pública e reconhecem os "interesses" do Estado. Os moradores de Mogi das Cruzes, mesmo os que são proprietários, exibem uma passividade determinada pelo isolamento e pela ignorância. Nenhuma forma de inteligibilidade dos problemas políticos lhes é atribuída, nenhuma possibilidade de participação nos assuntos públicos é vislumbrada. Eles são vistos à margem da história.

O curioso é que, em algumas passagens, Saint-Hilaire também faz referência ao espírito ativo dos paulistas. Ao narrar a história da conquista do sertão ao longo dos séculos XVII e XVIII, chega a apresentar os sertanistas mestiços de São Paulo como "raça de gigantes" que explorou as imensas "terras desertas" da América portuguesa (SAINT-HILAIRE, 1972: 15-16). Porém, ao descrever sua viagem pelo interior da província, ele não manifesta o mesmo entusiasmo. Por vezes, o relato compara os paulistas 
com os europeus, indicando a precariedade das "idéias" dos primeiros:

Por menos culto que seja o europeu, por mais baixa que lhe seja a procedência, tem mais idéias do que os brasileiros que não possuem a mínima instrução. Este é o caso geral mesmo quando diz respeito a pessoas ricas.

O português da Europa viu com efeito tudo o que o brasileiro pode ver, e além disso conhece o país natal, o que lhe fornece assuntos para comparações a que os americanos estão alheios. (SAINTHILAIRE, 1974: 103)

O brasileiro, em especial o sertanejo, pouco "viu" o mundo civilizado - simbolizado aqui pelo "país natal" do português - e, portanto, não pode traçar "comparações" e produzir muitas "idéias". Restrito ao deserto selvagem, o homem do interior definha intelectualmente, conversa e pensa pouco, compara menos ainda, e praticamente não desenvolve suas faculdades intelectuais. Apesar do texto acima tratar do brasileiro de modo geral, o leitor de Saint-Hilaire sabe que ele está indicando característica costumeiramente atribuídas aos habitantes do interior. Alguns parágrafos adiante, o viajante, em uma das muitas comparações entre os mineiros e os paulistas, salienta que estes são em geral mais "estúpidos" e "acanhados", pois "revelam não somente extrema ignorância como ainda limitada inteligência e pouco critério" (SAINT-HILAIRE, 1974: 104). Os relatos da viagem por São Paulo contêm vários exemplos desse tipo de comparação, um deles elucida as razões pelas quais ele admira os mineiros: os paulistas não manifestam "nem a inteligência, nem a curiosidade dos mineiros", desconhecendo "tudo o que ocorria pelo mundo, podendo falar apenas dos objetos que os cercavam" (SAINT-HILAIRE, 1972: 278). Apesar de também indicar fatores raciais para a distinção, o naturalista acredita que os mineiros - na verdade refere-se aos habitantes das regiões mais urbanizadas - experimentam relações sociais mais ricas e dinâmicas que os caipiras de São Paulo, homens com 
O DESERTO DOS MESTIÇOS: O SERTÃO E SEUS HABITANTES...

muito dificuldade de diálogo e incapazes de responder perguntas simples.

Mas Saint-Hailaire não compara o paulista do sertão apenas com os mineiros. Também o morador da capital da província distingue-se do interiorano. No caso, o viajante oferece pistas de que a representação depreciativa do caipira é anterior aos relatos de viagem e parece ter sido assimilada pelos naturalistas estrangeiros. Lembro aqui uma conhecida passagem de Viagem à província de São Paulo:

Nenhuma dificuldade há em distinguir os habitantes da cidade de São Paulo dos das localidades vizinhas. Estes últimos, quando percorrem a cidade, usam calças de tecido de algodão e um chapéu cinzento, sempre envolvidos no indispensável poncho, por mais forte que seja o calor. Denotam seus traços alguns dos caracteres da raça americana; seu andar é pesado, e têm um ar simplório e acanhado. Pelos mesmos têm os habitantes da cidade pouquíssima consideração, designando-os pela acunha injuriosa de caipiras, palavra derivada provavelmente do termo corupira pelo qual os antigos habitantes do país designavam demônios malfazejos existentes nas florestas. (SAINT-HILAIRE, 1972: 171)

Para o francês, na pequena São Paulo do início do século XIX, é fácil identificar o caipira: as roupas quase ridículas e o comportamento tímido o denunciam; ele parece acanhado diante do mundo urbano. O naturalista frisa que os paulistanos o consideram inferior: a "alcunha injuriosa" pela qual é definido, o aproxima da monstruosidade demoníaca e do mundo selvagem das florestas. Não pretendo aqui julgar as referências etimológicas de Saint-Hilaire, porém, de certa maneira, elas inserem o homem do interior no jogo de imagens da floresta mítica, repleta de seres monstruosos. Por outro lado, aparentemente os próprios brasileiros introduzem o viajante em um quadro de representações no qual o caipira figura como ser estranho e desprezível, pois é notório que o observador estrangeiro assimila as caracterizações veiculadas pelos paulistanos. Seja como for, a passagem esclarece que o paulista "estúpido" e "acanhado", oposto aos mineiros, é o caipira do sertão.

HISTÓRIA, São Paulo, 28 (2): 2009 
Em outras passagens dos relatos da viagem à São Paulo, o francês insiste no definhamento intelectual desse personagem. Descrevendo episódio ocorrido em um rancho na beira da estrada para Goiás, ele manifesta incômodo com a atitude do indivíduo que o observava em profundo silêncio:

Enquanto descrevia e examinava as plantas, aproximou-se um homem do rancho, permanecendo várias horas a olhar-me, sem proferir qualquer palavra. Desde Vila Boa [Goiás] até Rio das Pedras [São Paulo], tinha eu tido quiçá cem exemplos dessa estúpida indolência. Esses homens, embrutecidos pela ignorância, pela preguiça, pela falta de convivência com seus semelhantes, e, talvez, por excessos venéreos prematuros, não pensam: vegetam como árvores, como as ervas dos campos. (SAINT-HILAIRE, 1972: 95)

Transformado em objeto do olhar e da curiosidade do silencioso caipira, destituído do posto de sujeito de conhecimento, o observador europeu parece perturbado e recusa a possibilidade de seu observador produzir alguma forma de saber a seu respeito. É necessário, então, negar qualquer sentido à observação do outro, supondo e denunciando sua apatia e estupidez. Para o cientista, o longo e discreto exame a que é submetido prova que seu observador é incapaz de pensar e de se comunicar. O explorador europeu deprecia a atitude pacata do caipira e procura explicá-la a partir das debilidades de seu caráter e de seu modo de vida. Assim, seu observador é considerado incapaz de entender e exprimir em palavras o que observa e, mais uma vez, afigura-se como preguiçoso, ignorante, enfermo e, acima de tudo, carente de "convivência com seus semelhantes". Curioso e paradoxal é que também o cientista examinava as plantas sem dirigir qualquer palavra ao caipira - trata-se de um encontro de homens em silêncio.

Segundo o naturalista, mesmo nos momentos de diversão, os caipiras permanecem apáticos. Comparados aos camponeses da França, os paulistas parecem taciturnos: os primeiros, reunidos no domingo, "cantam, riem, discutem", enquanto os outros "apenas 
falam, não cantam, não riem e mantêm-se tão tristes depois de ter bebido cachaça, como estavam antes da ingestão dessa bebida alcoólica" (Saint-Hilaire, 1972: 249-250). Nem a bebedeira anima a existência desses homens. Seu comportamento tranqüilo, de certo modo sereno, permitiria várias interpretações, todavia aqui ele é entendido como mais uma prova de "estúpida indolência".

Para Saint-Hilaire, fatores raciais e climáticos contribuem para essa suposta estupidez. Mas a insistência na tese do "espírito ativo" dos paulistas, atestado também por Spix \& Martius, sinaliza a possibilidade dos sertanejos progredirem mesmo com as limitações raciais e climáticas. Para tal, seria necessário superar um obstáculo muito pior: o isolamento.

$\mathrm{Na}$ verdade, Saint-Hilaire poucas vezes encontra um sertanejo completamente solitário, sem ligações com vizinhos e parentes. Logo na sequência da narrativa do episódio no rancho da estrada São Paulo-Goiás, o autor informa que, próximo ao local onde "examinava plantas", mora "grande número de homens, mulheres e crianças". Portanto, a "falta de convivência" de seu observador não deriva propriamente de sua solidão, mas da ausência de certas relações sociais consideradas fundamentais para humanizá-lo e retirá-lo de sua inércia vegetal.

Ao discutir os traços característicos dos mestiços de índias com portugueses, que compõem a maior parte da população da província de São Paulo, Saint-Hilaire (1972, p.170) explicita quais seriam essas relações:

Os mamelucos não herdaram apenas o gosto pela vida errante que caracteriza os indígenas, pois destes herdaram também a descuidada preguiça (...). Criados pelas indígenas, esses homens viviam em completo isolamento, desprezados pelos pais; ninguém procurava elevá-los da ignorância em que jaziam. Seus costumes eram, necessariamente, grosseiros.

É notável como o viajante desumaniza as mães indígenas dos mamelucos: seus filhos "viviam em completo isolamento", apesar da companhia materna - o que logicamente constitui uma contradição. De qualquer modo, insinua-se que as índias não 
proporcionam uma verdadeira "convivência" para esses descendentes de portugueses. Sua bagagem cultural, segundo o viajante, nada pode ensinar. A presença dos pais portugueses, ao contrário, teria retirado os mestiços da "ignorância" e introduzido bons costumes. É completamente desconsiderada a capacidade da cultura indígena formar indivíduos sociáveis. Sem a orientação dos europeus, os mamelucos adotam comportamentos que inviabilizam o desenvolvimento de relações sociais consistentes, já que eles se tornam nômades, grosseiros e preguiçosos. Assim, no sertão da América, a sociedade humana não se instituiu plenamente. Está sugerido que apenas a intervenção efetiva e constante dos europeus estabeleceria laços comunitários capazes de viabilizar ações coletivas duráveis e consistentes, superando o suposto isolamento. Enfim, só o processo civilizador comandado pela expansão européia fundaria uma verdadeira vida pública e educaria os apáticos mestiços americanos.

Ao descrever os proprietários rurais de Goiás, Saint-Hilaire apresenta o mesmo diagnóstico: suas relações interpessoais são precárias e desprezíveis. Mais uma vez, as experiências coletivas dos homens do interior não significam uma verdadeira sociabilidade:

A palermice e a grosseria demonstradas por esses infelizes não deve, pois, causar surpresa. As poucas pessoas com quem eles se comunicam de longe em longe e, unicamente no tempo da seca, são os tropeiros, afora o convívio com seus escravos e seus rudes empregados (camaradas). Nada há para despertar a sua inteligência, para reaviver os seus conceitos morais, e nada, por assim dizer, os liga à sociedade humana. (SAINT-HILAIRE, 1975b: 123)

A convivência entre proprietários, escravos e camaradas não pode instaurar, segundo Saint-Hilaire, uma "sociedade humana". Mesmo os descendentes de europeus corrompem-se em Goiás, pois sua inteligência definha e eles esquecem seus conceitos morais. A exemplo das relações entre os mamelucos e suas mães, o contanto entre os goianos não faz parte do universo 
propriamente humano e produz "palermas" infelizes. Todas essas passagens demonstram que o suposto isolamento do homem do interior não anuncia a completa falta de convívio entre os indivíduos, mas sim a ausência da civilização européia. Qualquer experiência social que não corresponda ao modelo existente na Europa, é vista como animalesca e desprezível, incapaz de contribuir para o aperfeiçoamento intelectual dos indivíduos e para o progresso de nossa espécie. Portanto, deve ser eliminada, deixando de comprometer o futuro do Brasil.

Solitário, à margem da história, o sertanejo "vegeta" no deserto. Os viajantes consagram uma imagem que talvez já estivesse sendo formulada ao longo do século XVIII. Vejamos um indício desse processo. Em 1797, Francisco de Souza Coutinho, a serviço da Coroa portuguesa, escreve um relato de viagem que avalia as possibilidades de navegação entre o Mato Grosso e o Pará. Ao analisar os mato-grossenses que não eram indígenas, ele conclui: "o poderoso inimigo destes habitantes, e a mais poderosa causa, entre muitas outras, do seu atraso, é a preguiça deles"; então, ele aconselha as autoridades a cobrar tributos pelo "privilégio" de estabelecimento na área, forçando sua integração ao Império Português, pois, de outra forma, os mato-grossenses "não farão mais que vegetar inutilmente" (Coutinho, 1840: 303304). O homem que "vegeta" em uma natureza exuberante é uma representação que terá vida longa. Lembremos, por exemplo, o Jeca Tatu de Monteiro Lobato (1969: 277-293). Sua gênese articula-se com o surgimento das descrições científicas da realidade brasileira realizadas pelos naturalistas. Para os autores aqui estudados, ocupar o sertão e explorá-lo significa salvá-lo da desordem, da ignorância, da inércia e do isolamento. Significa introduzi-lo na história da civilização e, enfim, humanizá-lo. Seria possível afirmar que esse projeto civilizador foi bem sucedido? 


\section{Referências Bibliográficas}

AMADO, Janaína. Região, sertão, nação. Estudos Históricos, Rio de Janeiro, v. 8, $\mathrm{n}^{\circ}$ 15, $1995 . \quad$ Disponível em: www.cpdoc.fgv.br/revista/arq/169.pdf. Acesso: 27/12/2007.

Actas da Câmara da Villa de São Paulo - 1596/1622. São Paulo: Duprat, 1915, v. 2.

COUTINHO, Francisco de Sousa. Informação sobre o modo porque se efetua presentemente a navegação do Pará para Mato Grosso - Copiada de um manuscripto offerecido ao Instituto pelo Cônego J. da C. Barbosa. Revista Trimestral do Instituto Histórico e Geográfico Brasileiro, Rio de Janeiro, v. 2, $\mathrm{n}^{\circ} 7,3^{\circ}$ trimestre de 1840.

ELIAS, Nobert. O processo civilizador. Rio de Janeiro: Jorge Zahar, 1990, V. 1.

LE GOFF, Jacques. O maravilhoso e o quotidiano no ocidente medieval. Lisboa: Edições 70, 1985.

LE GOFF, Jacques. Para um novo conceito de Idade Média. Lisboa: Estampa, 1993.

LIMA, Maria Emília A. Torres. As caminhadas de Auguste de SaintHilaire pelo Brasil e Paraguai. Belo Horizonte: Autêntica, 2002.

LISBOA, Karen M. A Nova Atlântica de Spix e Martius. São Paulo: Hucitec/FAPESP, 1997.

LOBATO, Monteiro. Urupês. São Paulo: Brasiliense, 1969.

SAINT-HILAIRE, Auguste de. Viagem às nascentes do rio São Francisco. Belo Horizonte: Itatiaia; São Paulo: Editora da USP, 1975a.

SAINT-HILAIRE, Auguste de. Viagem à província de Goiás. Belo Horizonte: Itatiaia; São Paulo: Editora da USP, 1975b.

SAINT-HILAIRE, Auguste de. Segunda viagem do Rio de Janeiro a Minas Gerais e a São Paulo (1822). Belo Horizonte: Itatiaia; São Paulo: Editora da USP, 1974.

SAINT-HILAIRE, Auguste de. Viagem à província de S. Paulo. São Paulo: Livraria Martins/Editora da USP, 1972.

SIPX, Johann von; MARTIUS, Carl von. Viagem pelo Brasil. São Paulo: Melhoramentos, s/d, v. 1

SIPX, Johann von; MARTIUS, Carl von. Viagem pelo Brasil. São Paulo: Edições Melhoramentos, 1976, v. 2.

VENTURA, Roberto. Visões do deserto: selva e sertão em Euclides da Cunha. História, ciência, saúde - Manguinhos, Rio de Janeiro, v. 5, julho de 1998. Disponível em: 
www.scielo.br/scielo.php?script $=$ sci_arttext\&pid $=$ S01045970199800040 0008. Acesso: 08/08/2008.

MIRANDA, Luiz Francisco A. de. The Mestizo Desert: The Backlands and Their Inhabitants in Travel Records from the Early $19^{\mathrm{TH}}$ Century. História, v.28, n.2, p.621-644, 2009.

\begin{abstract}
The objective of this paper is to analyze the representations of the backlands in the works by travelers and naturalists August de Saint-Hilaire and Johann von Spix \& Carl von Martius, who traveled Portuguese America in the early $19^{\text {th }}$ century. This study exclusively investigates the travel records from trips taken to the interior of the provinces of Sao Paulo, Minas Gerais and Goias. The naturalists, led by European cultural references, strove to recognize and understand the areas which were still not considered civilized and yet were at the frontiers of colonization. The backlands, defined as a barbarian and desertic environment, poses a challenge for the scientists, who projected the progress of Brazilian society.
\end{abstract}

Keywords: Backland; Civilization; Saint-Hilaire; Spix \& Martius.

Artigo recebido em 04/2009. Aprovado em 07/2009. 